
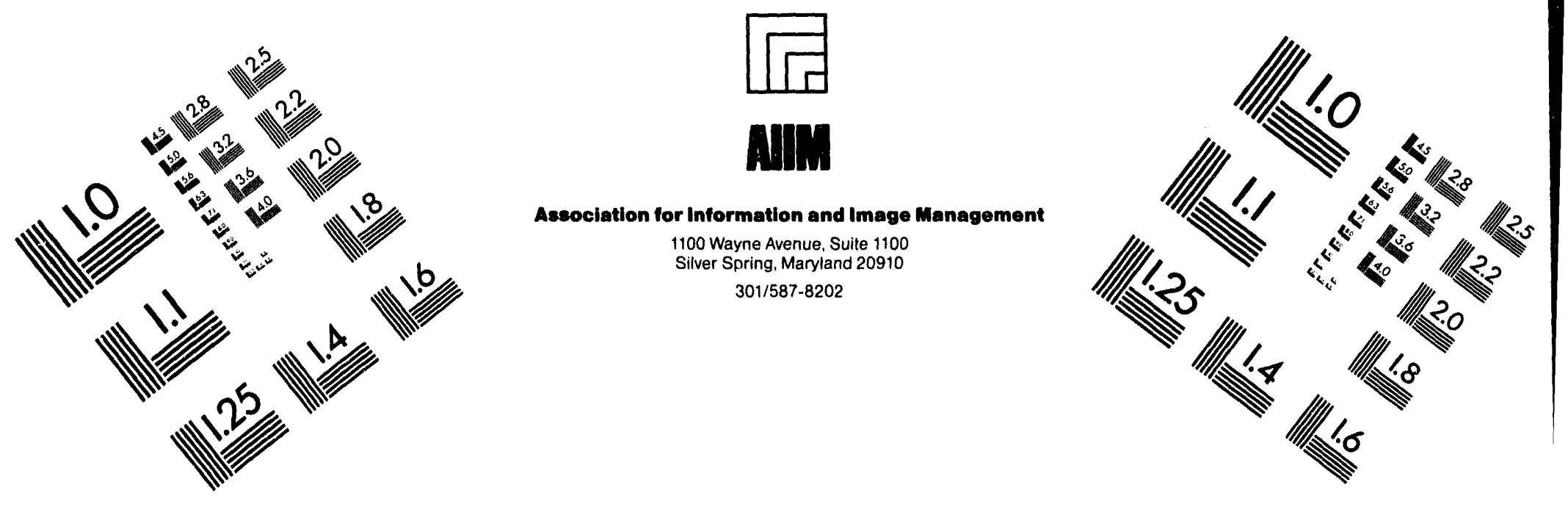

\title{
Centimeter
}

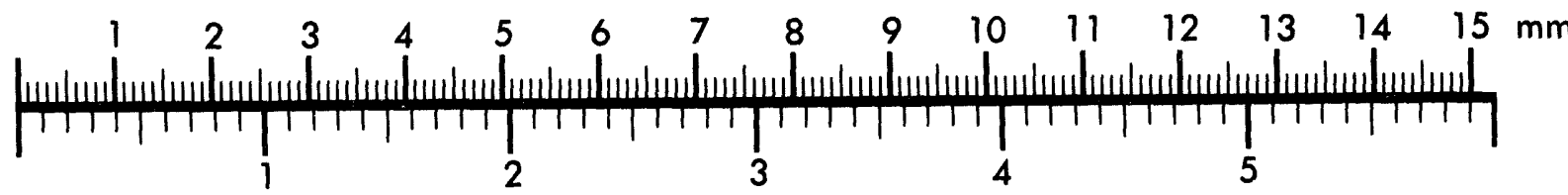
Inches
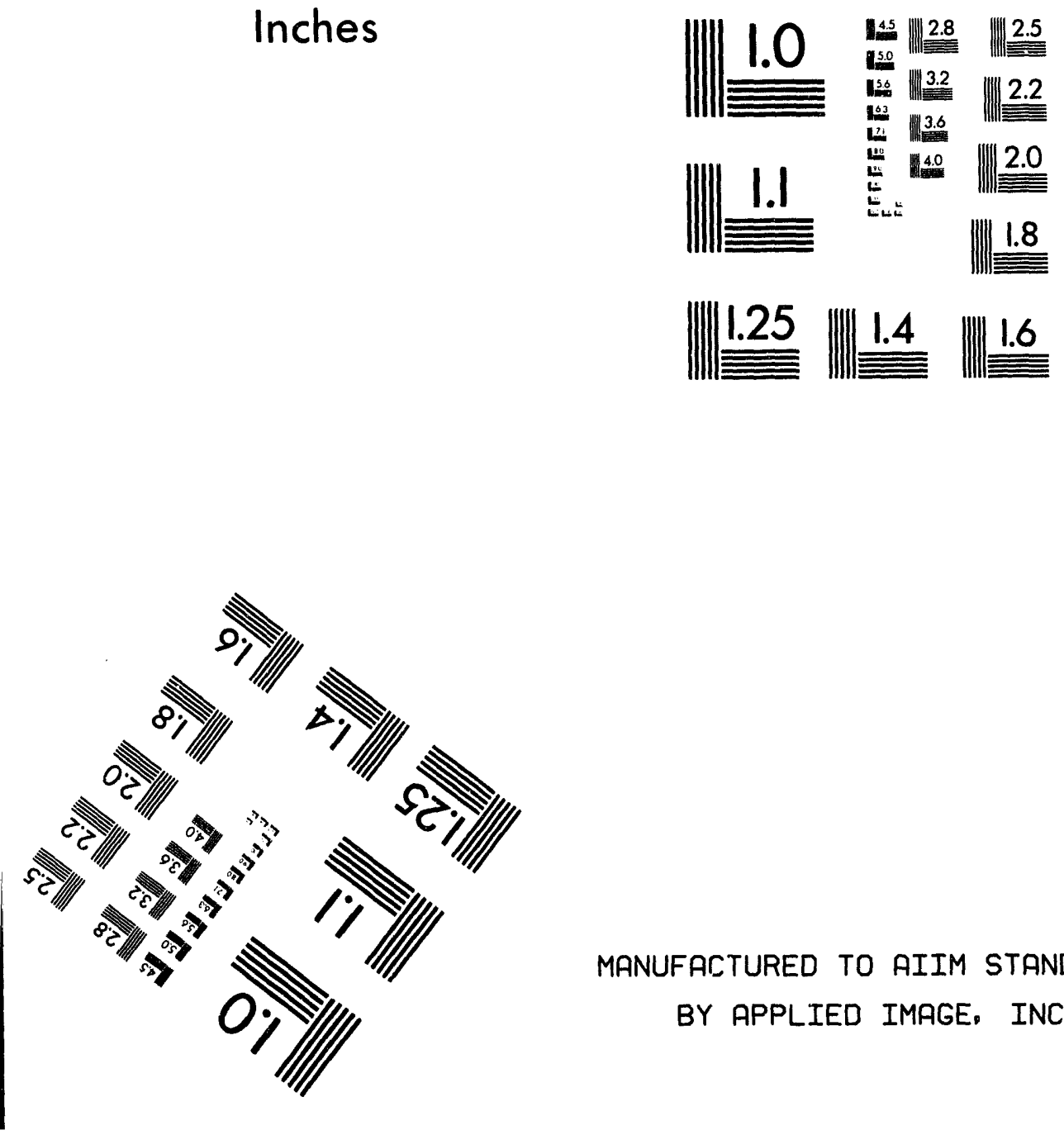

MANUFACTURED TO AIIM STANDARDS

BY APPLIED IMAGE. INC.

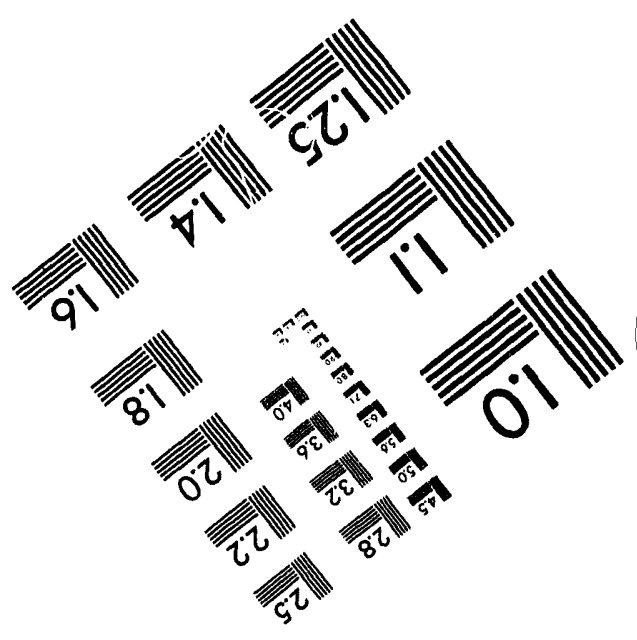



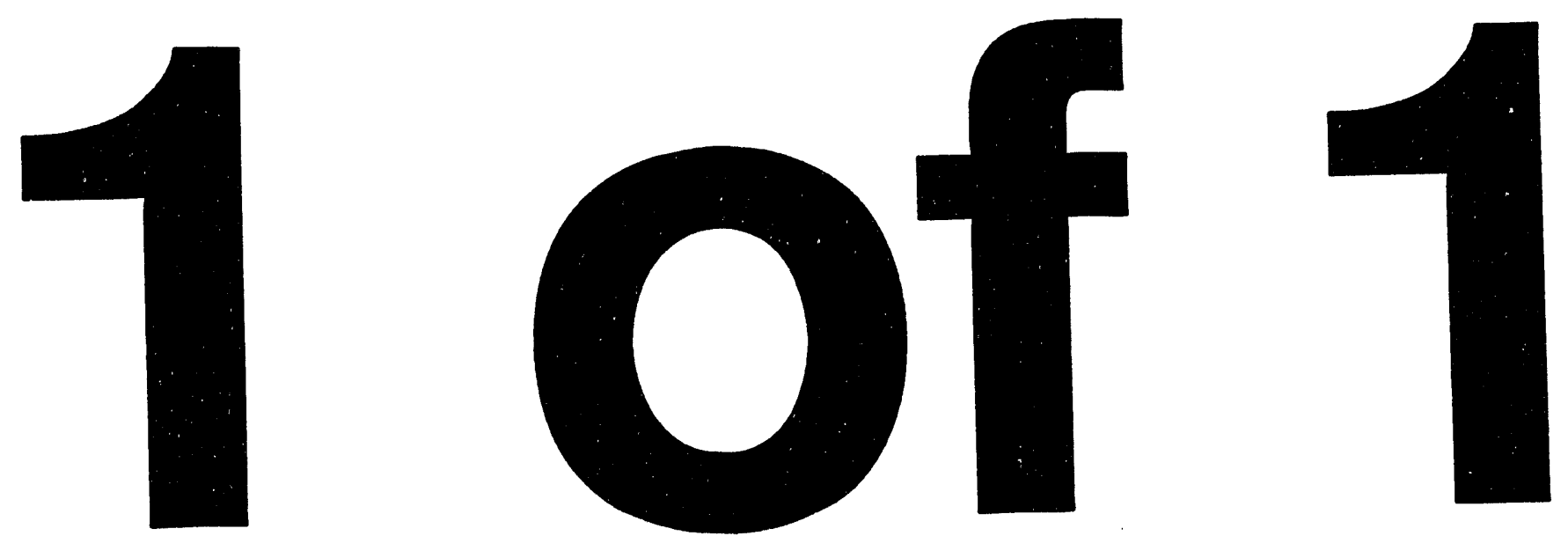
DECLLSSFFIED

(CLASSIFICATION)

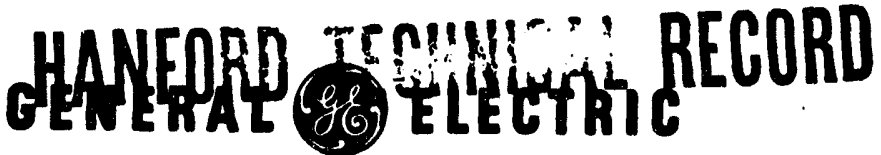

MANFOND ATOMIC PRODUCTB OPERATION - RICHLAND, WABHINGTON

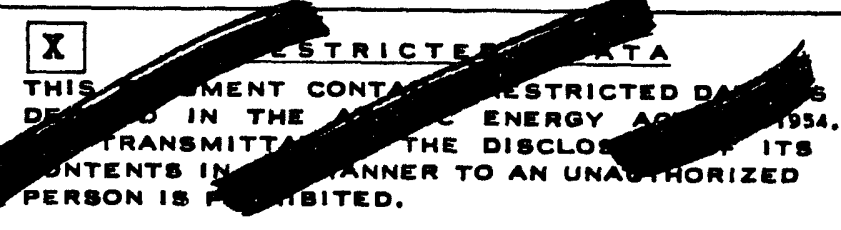
TITLE

HW-58102 REV.

BERIES AND COPY NO.

8 .

May 6, 1959

\section{FRINGE ISOTOPE PRODUCTION}

\section{$\square$ OTHER OFFICIAL CLABSIFIED INFORMATION}

THIS MATERIAL CONTAINS INFOAMATION AFFECTING THE NATIONAL DEFENBE OF THE UNITED STATES WITHIN THE MEANING OF THE EBPIONAGE LAWS. TITLE 18, U. B. C., SECS. TOS AND TOA, THE TRANSMISSION OR REVELATION OF WHICH IN ANY MANNER TO AN UNAUTHORIZED PERSON IS PROHIBITED EY LAW.

AUTHOR

W. I. Bunch

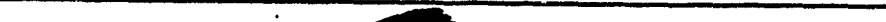

THIS DOCUMENT MUN OE LEFT UNATTENDED OR TO IT. WHEN NO SE, IT MUST DE STORED

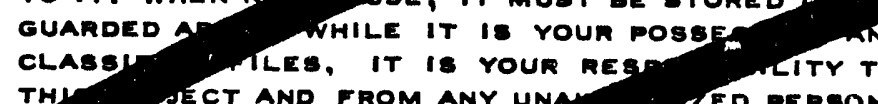
THI SECT AND FROM ANY UNA

ASIDENCE IS PROHIBIT: TS NOT TO DE DUPLIGNANS

TAIN THEM FROM THEIT DO IS NOT TO DE DUPLIG TO SION IN THE SPACE PRÓNIDED EELOW.

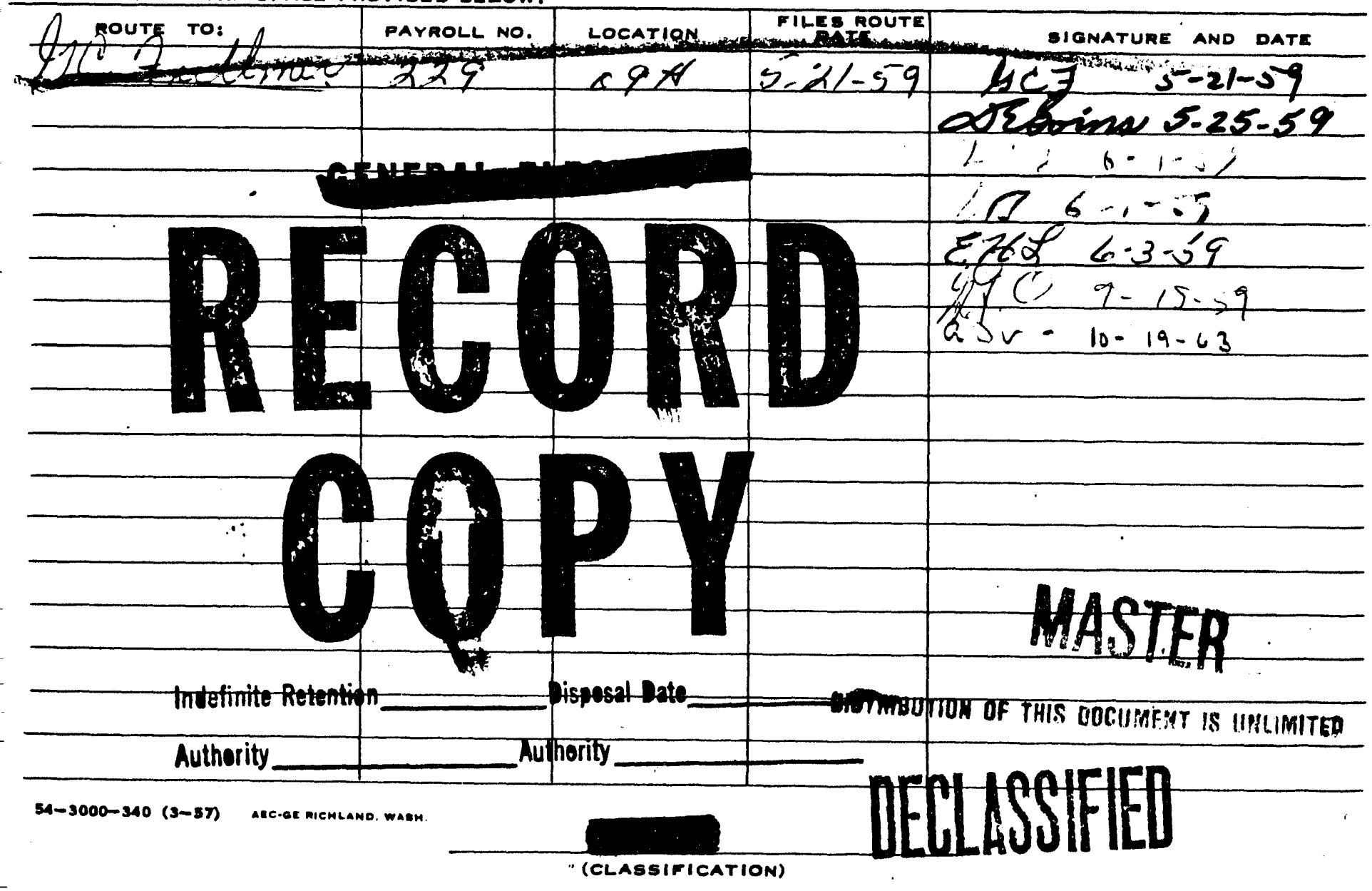




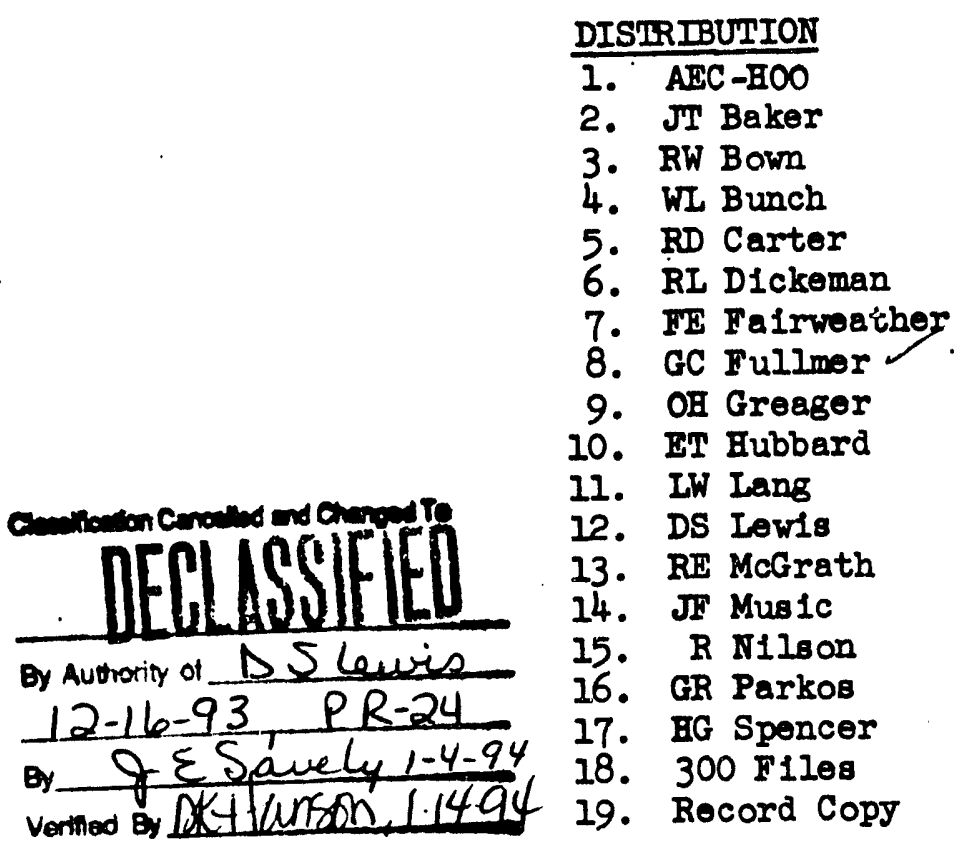

\section{DECLLSSFFIED}

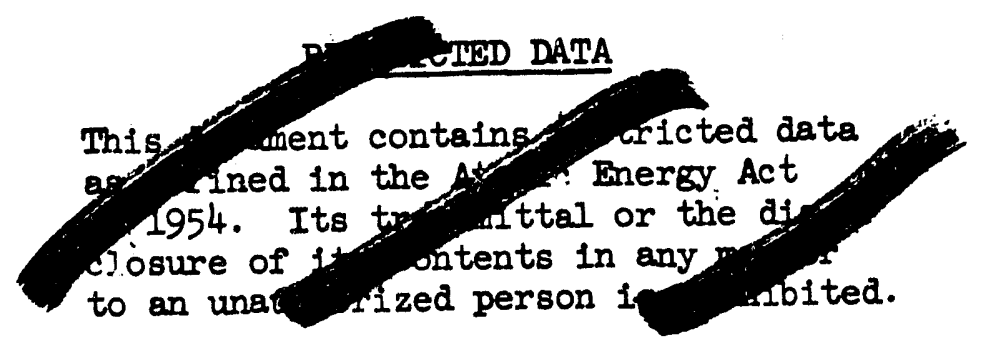

This document consists of $\frac{7}{19}$ copies. Series

This document classified

by He Fullmen:

May 6, 1959

\section{FRINGE ISOTOPE PRODUCTION}

\section{INTRODUCTION}

The purpose of this work has been to determine experimentally the rate of production of tritium in fringe lithium-aluminum alloy loadings with the degree of precision necessary for economic analyses of such a method of isotope production $(1,2)$. These results are provided for use in such an analysis.

\section{SUMMARY}

The production rate of tritium in the outermost fringe tubes is related to the heat generation in the enriched material in the adjacent lattice by the equation:

$$
T=0.0021 M_{\text {adj }}
$$

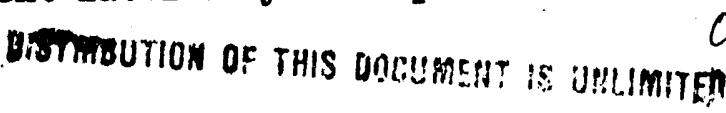


SURAARY (Continued)

where $\quad T=$ Grams of tritium per full length charge (64 four-inch pleces) of Ilthivil-aluminum alloy material (concentration 3.5 per cent natura! I1thium)

$M_{a d j}=$ MWD of heat generated in the adjacent enriched column normalized on a per ton basis

The experimental constant $(0.0021)$ is estimated to be accurate to plus or minus ten per cent. The constant should apply also to fringe losds utilizing somewhat greater or smaller quantities of enrichment than that employed in the test, that is for isotope production loadinge which are slightly over or under-compensated from a reactivity standpoint.

A numerical evaluation of the production in the test loading plus the central natural uranium columns indicates that 80 atoms of $T$ and 2300 atoms of Pu would be produced while 2826 atoms of U-235 would be consumed. For a natural uranium loading in the test zone it is calculated that 2410 atoms of Pu would have been produced and 2909 atoms of U-2.35 consumed in the same columns during a similar operating interval. It appears that the atom conversion ratio of the reactor could be increased by about one per cent by the use of complete fringe poison loadings.

The accuracy of this experimental evaluation is limited by the large variation in the radioactivity of the cobalt pleces used to measure the neutron flux in various parts of the loading. In the present analysis $1 t$ was assumed that the average found in the test load would be representative of any large scale reactor loading. It is felt that actual processing of significant quantities of material is necessary to obtain a really good evaluation of conversion efficiency.

\section{DESCRIPTION OF TEST}

Isotope production rates in materials placed within a reactor are governed by the neutron flux in which the material resides. In the case of fissionable materials the neutron flux can be evaluated from the heat generation rate in the column of metal. In full length 1sotope production columns the heat generation 1 s small and some other method must be used to determine the flux. The radloactivity of cobalt samples irradiated in experimental metal charges has been used to relate the flux level in the fringe mint columns to the flux level (as indicated by heat generation rate) in the adjacent $\mathrm{E}$ metal columns.

Cobalt has a long half-Iife ( 5.2 years) compared to the length of the Irradiation used in this test (approximately six months); hence, the radioactivity of the cobalt pieces is almost directly proportional to the integrated exposure $(\phi t)$. The cobalt-aluminum mixture which was used in the test was designed to absorb neutrons at the same rate as either B-metal or mint material. Therefore, the volume average flux in an isolated cobalt-aluminum plece should be representative of the volume average flux in the E-metal or mint plece which it displaced.

Four pairs of mint and E-metal columns were used in the fringe poison losd at the DR Reactor. Cobalt pieces were centered with mint in tubes 1896-DR and 2296-DR; matched cobsit pieces were centered with B-metal in tubes 1894-DR and 2294-DR. Ilkewise, cobalt pleces were placed one-quarter of the way from the downstream end of the active charge in tubes 2096-DR and 2596-DR (w1th mint) and in tubes 2094-IR and 2594-DR (w1th B-metal). Dally readings of the flow and temperature rise on these E-metal charges
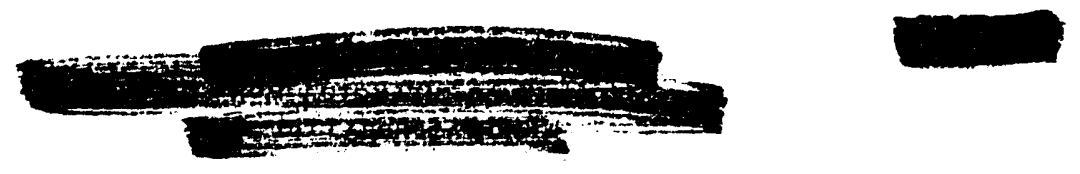
and also on the E-metal charges on the corresponding rows in column 95 were taken. After discharge the numbered $\mathbf{E}$ metal pleces were weaseled to obtain the front-to-rear flux distribution, and the cobalt pieces were weaseled to obtain the flux ratio between the I-metal charges and the mint charges.

\section{A. Derivation of Production Relations}

It is assumed that the amount of tritium produced in a full length column of mint slugs is given by the equation:

$$
T=\bar{\phi}_{p}+\mathbb{N}_{6} \sigma_{\mathrm{a}} \mathrm{w}
$$

where $T=$ grams of tritium per tube of mint

$\bar{\phi}_{p}=$ volume average $f I u x$ in the mint, $\mathrm{n} / \mathrm{cm}^{2} \mathrm{sec}$

$t=$ exposure time, seconds

$N_{6}=$ number of atoms of Li-6 in a tube of mint

$\sigma_{a}=$ absorption cross section for $\mathrm{n}, \propto$ process, $\mathrm{cm}^{2}$

$w=$ grams of tritium per atom of tritium

Likewise the integrated exposure of the charge of E-metal in the tube inmediately adjacent to the mint column is:

$$
M_{a d j}=\bar{\phi}_{a d j} t H_{f} \quad \mathbb{N}_{25} \sigma_{f} \quad(1+\delta)
$$

where

$M_{a d j}=$ MWD per adjacent ton of E-metal (MWD/AT)

If = heat of fission, assumed to be $200 \mathrm{Mer}$

$(1+\delta)=$ fast effect, taken as 1.057

$\mathrm{N}_{25}=$ atoms of U-235 per ton of E-metal:

$\sigma_{f}=$ Pission cross section of U-235, $\mathrm{cm}^{2}$

c = energy conversion constant, $1.854 \quad 10^{-24} \mathrm{MWD} / \mathrm{Mev}$

Because the cobalt-aluminum pleces were not irradiated in the adjacent columns it is necessary to include also the experimental columns:

$$
M_{\text {exp }}=\bar{\phi}_{\exp } t \mathrm{H}_{f}(1+\delta) N_{25} \sigma_{f} c
$$

where the meanings are as before and the subscript "exp" stands for experimental.

As stated before, the radioactivity of the cobalt pieces is a measure of the integrated flux at that point. Assuming the same front-to-rear flux to exist in both the E-column and mint column the following relation should hold for pleces irradiated at the same relative location in the charge: 


$$
\frac{\bar{\phi}_{p} t}{A_{p}}=\frac{\bar{\phi}_{\exp } t}{A_{\exp }}
$$

where A represents the cobalt-aluminum activity in any arbitrary unit. Substituting this value of $\bar{\phi}_{p} t$ in equation (I) ylelds:

$$
T=\frac{\bar{\phi}_{\exp } t}{A_{\exp }} A_{p} N_{6} \sigma_{a} w .
$$

Dividing by the exposure of the adjacent metal:

$$
\frac{T}{M_{a d j}}=\frac{A_{p}}{A_{e x p}} \frac{\bar{\phi}_{\exp } t}{M_{a d j}} N_{6} \sigma_{a} \text { w. }
$$

Using equation (3) to evaluate $\bar{\phi}_{\exp }$ t:

$$
\frac{T}{M_{a d j}}=\left(\frac{A_{p}}{A_{\text {exp }}}\right)\left(\frac{M_{\exp }}{M_{a d j}}\right)\left(\frac{N_{6} \sigma_{a}}{N_{25} \sigma_{f}} \frac{w}{H_{p}(1+\delta)_{c}}\right)
$$

B. Evaluation of Production Relation

The production relation (equation 4) is the product of three ratios. The first two of these were determined experimentally in this production test; the other can be calculated using accepted values of material composition, cross sections, etc. The evaluation of these ratios will be discussed briefly.

1. $A_{p} / A_{\exp }$ - The ratio $A_{p} / A_{\exp }$ was obtained in four separate cases - two each for the central location of the charge and two each for the downstream location. Unfortunately, a large variation was found to exist in these ratios. The central values were found to be 0.550 ( 18 row) and 0.516 (22 row), whereas the downstream values were 0.481 (20 row) and 0.454 ( 25 row). A definfte systematic variation can be seen in these ratios: the ratios increase from the top to the bottom of the load and increase from the downstream end to the center of the load. The reason for this variation is not apparent. The weasel data of the E-metal gave a reasonably smooth cosine distribution for all the charges; there is no reason to suspect that the distribution in the mint should be materially different. For lack of a better method, a simple average of the four experimental ratios was assumed to be realistic $(0.50)$. An estimated accuracy of plus or minus 10 per cent is associated with this value.

2. $M_{\exp } / M_{a d j}$ - Over four hundred determinations of the tube power of the experimental E-metal column's and the adjacent E-metal columns were obtained during the test period to evaluate the exposure ratio $M_{\text {exp }} / M_{\text {adj }}$. With an estimated accuracy of plus or minus four per cent on the individual determinations, the resulting ratio of 1.377 is calculated to be within plus or minus 0.2 per cent. No significant variation in this ratio was noted except for the

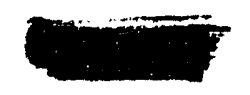


charges in the 18 row which gave a consistently lower ratio. This is attributed to the fact that all rows below 18 were filled with natural uranium (Instead of the enrichment-poison loading); hence, the buckling was less. This "edge" effect would be assoclated with any small fringe polson load short of a complete blanket.

3. Ratio of Material Constants - The evaluation of the ratio of the macroscopic cross sections of the two materials requires simply a knowledge of material composition. It was assumed that mint was 3.5 per cent natural lithium; that 1s, 3.5 grams of 11 thium plus 96.5 grams of aluminum equal 100 grams of mint. On a volume basis this means there are $0.1549 \mathrm{~cm}^{3}$ of 11 thium per $\mathrm{cm}^{3}$ of mint. A full length charge of mint consists of 67 pieces with each plece having a core length of 3.80 inches. Thus,

$$
\begin{aligned}
N_{6} & =67\left[\pi(0.682)^{2}(3.80)(2.54)^{3}\right](0.1549)(0.075)\left(0.0463 \cdot 10^{24}\right) \\
& =3.278 .10^{24} \text { atoms of } L_{1}-6 \text { per tube of mint }
\end{aligned}
$$

where natural I1thium is assumed to be 7.5 per cent isotope 6 and there are $0.0463 \cdot 10^{24}$ atoms of I1thium per $\mathrm{cm}^{3}$ of 11thium. The value of $\sigma_{a}$ is 940 barns and the welght of tritium is $5.008 \cdot 10^{-24}$ grams per atom. Thus, the numerator becomes:

$$
N_{6} \sigma_{Q} w=(3081)\left(5.008 \cdot 10^{-24}\right)=15,430 \cdot 10^{-24}
$$

The E-metal 1s assumed to be 0.95 per cent U-235; therefore,

$$
\begin{aligned}
& N_{25}=9.072 \cdot 10^{5}\left(\frac{\mathrm{gm} \text { of } \mathrm{E}}{\text { ton of } \mathrm{E}}\right) 6.023 \cdot 10^{23}\left(\frac{\text { atom of } \mathrm{E}}{\text { at wt }}\right) \frac{1}{238}\left(\frac{\text { at } \mathrm{ut}}{\mathrm{E}}\right) 0.0095 \\
& \text { atom of } 25 \text { ) } \\
& =22.08 \cdot 10^{24} \text { atoms } 25 \text { per ton of } \mathbf{E} \text {. }
\end{aligned}
$$

Also

$$
\begin{aligned}
\sigma_{E} & =584 \cdot 10^{-24} \mathrm{~cm}^{2} \\
H_{P} & =200 \mathrm{Mev} / \text { fission } \\
(1+\delta) & =1.057 \\
c & =1.854 \cdot 10^{-24} \mathrm{MWD} / \mathrm{Mev} .
\end{aligned}
$$

The denominator of the ratio becomes:

$$
\begin{aligned}
\mathbb{N}_{25} \sigma_{f} H_{f}(1+\delta) c & =\left(22.08 \cdot 10^{24}\right)\left(584 \cdot 10^{-24}\right)(200)(1.057)\left(1.854 \cdot 10^{-24}\right. \\
& =5,053,900 \cdot 10^{-24}
\end{aligned}
$$


DESCRIPTION OF TEST (Continued)

The ratio

$$
\frac{N_{6} \sigma_{a} w}{N_{25} \sigma_{f} H_{1}(1+8) c}=\frac{15,430 \cdot 10^{-24}}{5,053,900 \cdot 10^{-24}}=0.00305
$$

4. $T / M_{a d j}$ - The numerical evaluation of equation 4 is:

$$
\frac{T}{M_{\text {adj }}}=(0.50)(1.377)(0.00305)=0.0021 \frac{\text { sms of } T \text { per tube of mint }}{\text { wFD per adjacent ton of } E}
$$

An evaluation of the uncertainties indicates the accuracy of this conversion constant to be about ten per cent. The primary source of the uncertainty is introduced by the wide spread in cobalt slug activities which was obtained.

C. Numerical Example

To calculate the relative production efficiency of the mint loading the flux distribution in the fringe region before and after placing the poison-enrichment is used (see reference 2). The production along one row of tubes from the center to the far side of the reactor is considered as the basis of comparison. This should be conservatively realistic of a complete blanket loading. Using an arbitrary central power of one $\mathrm{MW}$ per tube in the flattened zone the heat generation before the test load is $20.95 \mathrm{MW}$. After the poison-enrichment load the power is $20.30 \mathrm{MW}$ where $18.84 \mathrm{MW}$ is generated in natural uranfum and $1.46 \mathrm{MW}$ is generated in the E-metal. The E-metal adjacent to the mint is operating at $0.43 \mathrm{MW}$ per tube or $3.5 \mathrm{MW}$ per ton. In 136 full power operating days the mint column will produce one gram of $\mathrm{T}$ :

$$
T=136 \text { days } 3.5 \frac{\mathrm{MW}}{\mathrm{TOn}} 0.0021 \quad \frac{\mathrm{T} T / \text { tube }}{\mathrm{T}}=1 \text { of } \mathrm{T}
$$

During this same period of time the natural uranium generates $(136)(18.84)=2562$ MWD and the E generates $(136)(1.46)=199$ MWD. If the lood had not been present the heat generation would have been $(136)(20.95)=2849$ MWD.

To calculate plutonium production and U-235 burnout; average factors for I \& $\mathrm{E}$ natural and for solld $\mathrm{E}$ irradiated to $800 \mathrm{kWD} / \mathrm{T}$ were used. These values are:

$\begin{array}{lccc} & \frac{\text { Plutonlum Made }}{\mathrm{B} / \mathrm{MWD}} \frac{\mathrm{U}-235: \text { Consumed }}{\mathrm{B} / \mathrm{MWD}} & \text { Reference } \\ \text { I and E Natural } & 0.846 & 1.021 & \text { (3) } \\ \text { Solid E } & 0.666 & 1.057 & \text { (4) }\end{array}$

The production and burnout in grams becomes: 


\begin{tabular}{|c|c|c|c|c|c|}
\hline \multirow[t]{2}{*}{$\cdot$} & \multirow[b]{2}{*}{ Pu. } & \multicolumn{2}{|r|}{$T$} & \multirow[b]{2}{*}{$\mathrm{U}-235$} & \multirow{2}{*}{$\begin{array}{l}\text { Atom } \\
\text { Conversion Efficlency }\end{array}$} \\
\hline & & Actual & Pu-equivalent & & \\
\hline $\begin{array}{l}\text { Before } \\
\text { After }\end{array}$ & $\begin{array}{l}2410 \\
2300\end{array}$ & $\begin{array}{l}0 \\
1\end{array}$ & $\begin{array}{r}0 \\
80\end{array}$ & $\begin{array}{l}2909 \\
2826 .\end{array}$ & $\begin{array}{l}0.828 \\
0.842\end{array}$ \\
\hline
\end{tabular}

where the conversion efficlency is on a per atom basis. It is apparent that the overall pile conversion efficiency would be increased by the Irradiation of a fringe 1sotope production load. This remains true even if the tritium production is considerably less than that determined by the experiment. However, the advisabllity of utilizing fringe 1sotope production depends on the relative economic value of the products, on the operational handling and separations problems involved, and on other side effects such as shield protection, rather than simply on the conversion efficiency.

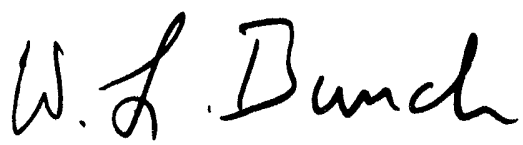

Irradiation Testing Sub-Section Research and Engineering Section (Work performed in Operational Physics Sub-Section)

WL Bunch:mwe

\section{References:}

1. HW-51723, "Interim Report, Operational Physics Aspects of Production Test IP-14-AC, Use of E-Metal in Shield Protection," W. I. Bunch, 9-18-57.

2. BW-53345, "Supp. B, PT-IP-14-AC, Use of E-Metal in Shield Protection," W. L. Bunch, L. W. Lang, 10-25-57.

3. HW-50300-B, "IPD Reactor SS Material Conversion and Bias Calculation Tables," W. B. Niemuth, 12-57.

4. BwN-1299, Personal Notebook, R. O. Gumprecht. 

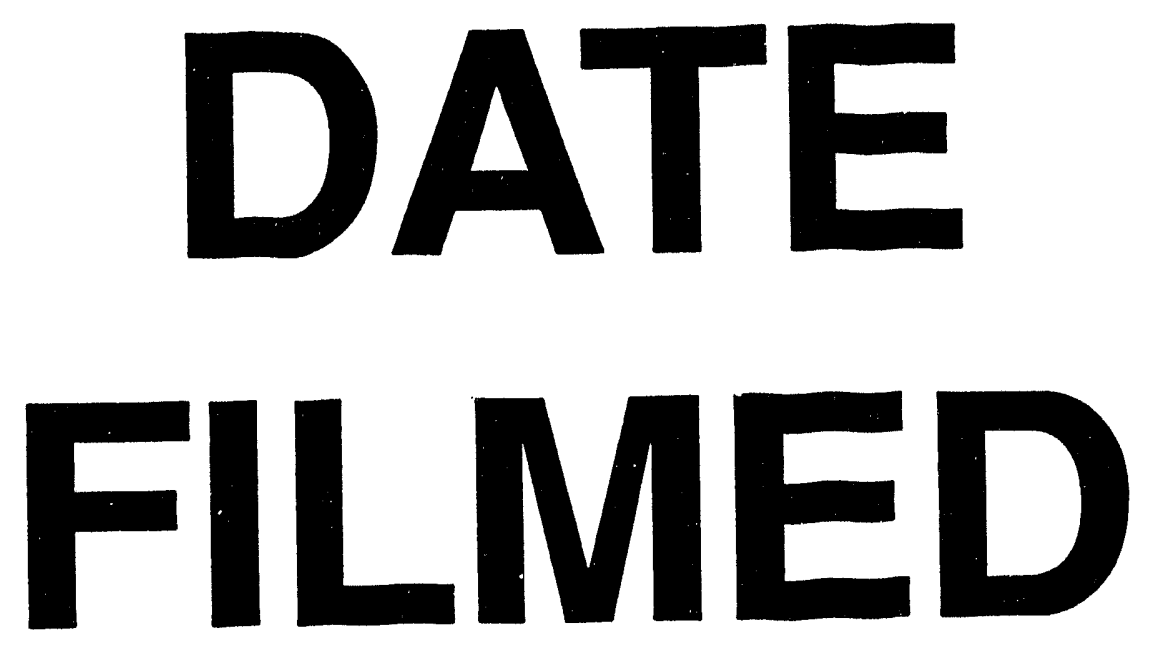

$9 / 16 / 94$
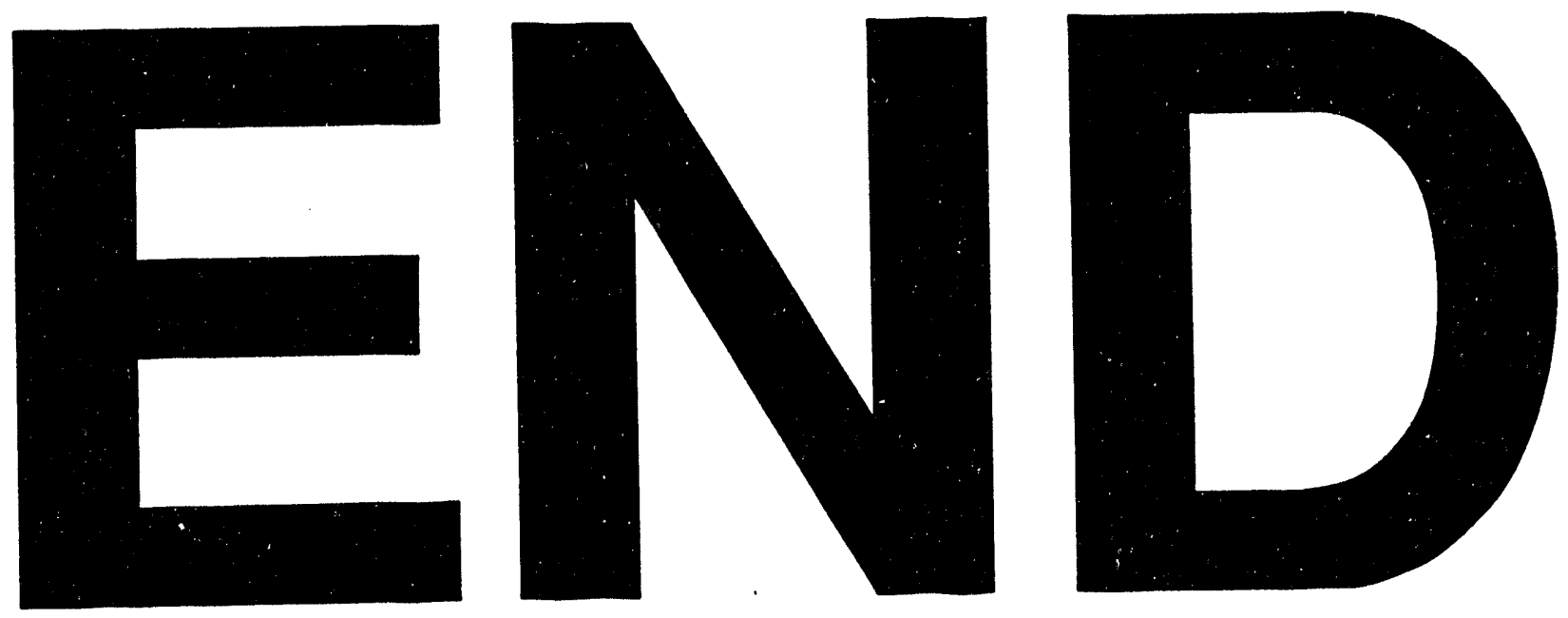


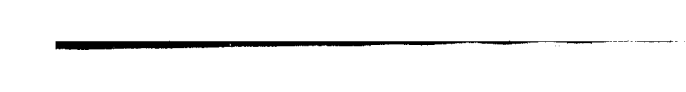

